\title{
Ethical concerns and legal challenges in revenue and pricing management
}

\author{
Jean-Pierre van der Rest ${ }^{1} \cdot$ Lorna Wang $^{2} \cdot$ Li Miao $^{3}$
}

Published online: 29 February 2020

() Springer Nature Limited 2020

Over the past two decades, we have seen phenomenal developments in the field of pricing and revenue management (RM). This is exemplified by the rise of e-commerce, artificial intelligence, and big data analytics which have influenced pricing and RM decision-making processes at both strategic and functional levels. Driven by competitive pressures and financial interests, we have witnessed how sophisticated RM systems and pricing practices have become datadriven, impacting the revenue growth. But, what are the downsides to this; what are the costs? While little attention has been paid to ethical concerns in RM, the increased use of automation and consumer data have prompted much debate in the public arena, and subsequently pricing practices have come under greater legislative and regulatory scrutiny globally in recent years. The "dark side" of algorithmic pricing thus appears to have emerged, though has yet to be fully explored. This special issue aims to draw scholarly attention to ethical and legal concerns in pricing and RM, particularly as they relate to the hospitality and tourism industry. It intends to initiate more critical discussions on issues such as injustice, unfairness, dishonesty, and misconduct in pricing and RM practices that could impact the field for many years in the future.

\section{Jean-Pierre van der Rest}

j.i.van.der.rest@law.leidenuniv.nl

Lorna Wang

lorna.wang@ surrey.ac.uk

Li Miao

lm@okstate.edu

1 Department of Business Studies, Leiden Law School, Institute for Tax Law \& Economics, Leiden University, Steenschuur 25, 2311 ES Leiden, The Netherlands

2 School of Hospitality and Tourism Management, University of Surrey, Surrey GU2 7XH, UK

3 School of Hospitality and Tourism Management, Oklahoma State University, Stillwater, OK 74078, USA
This special issue includes research papers exploring fairness or ethical perceptions of pricing and RM practices from multiple stakeholders' perspectives. It begins with Gerlick and Liozu's qualitative research into the ethical and legal considerations of artificial intelligence and algorithmic decision-making in personalized pricing. A conceptual model is presented based on systematic literature review to explain how companies couple organizational and technology factors into price-setting process. As many revenue practitioners embrace algorithmic decision-making, this paper is one of the first studies that offers insights into the implications of personalized pricing using algorithmic models based on findings from previous studies as well as discussions with senior pricing managers and executives.

Taking an experimental approach, Priester, Robbert, and Roth examined the effects of personalized dynamic pricing on consumer fairness perceptions. They explored consumers' fairness perceptions of individual prices, segment prices, location-based pricing, and purchase history-based pricing. The research dissected personalized dynamic pricing based on the degrees of price individualization and the underlying segmentation criteria, building a stronger conceptual basis to examine the effects of personalized dynamic pricing on consumer perceptions.

In a viewpoint on personalized pricing, Van der Rest, Sears, Wang, and Miao reflected on how legislators and regulators in Europe seek to limit some recent developments in pricing, in particular with regard to the use of personalized pricing. They conclude that not much is to be expected from the legal system, at least not in the short run, with regard to guiding the pricing and RM field in setting and implementing minimum standards of behavior. In their view, scholarly attention should not only be directed to the ethical concerns of new forms of direct price discrimination, such as personalized dynamic pricing, but should also go out to the ethics of indirect price discrimination, through which consumers are 'nudged' to sort themselves into different microsegments, especially when the 'self-selection' 
is enticed by deceptive applications of psychological pricing and neuromarketing.

Haynes and Egan took an employee perspective and explored the perceptions of frontline employees towards hotel overbooking practices. A qualitative approach supplemented by quantitative scenario testing was used in the research to engage hospitality frontline employees working in hotels who have been actively involved in the "walking of guests' and operationalizing overbooking strategies. The research used the host-guest relationship as a lens to explore ethical challenges associated with overbooking as perceived by frontline employees and suggested that employees' perceived ability to compensate guests and give advanced warning of an overbooking situation appeared to help frontline employees to maintain an ethical balance between hospitableness and commercially driven overbooking practices.

The recent lawsuits filed by a number of US states against certain hotel companies for alleged violating consumer protection laws have challenged the legality of charging hotel resort fees. In a last paper of this special issue, Belarmino, Raab, and Demirciftci reported their findings on the effect of resort fees on perceived fairness and destination brand image. They surveyed hotel guests who had been charged resort fees in the past 5 years and the results show that familiarity with resort fees and familiarity with the destination impacted the perception of resort fee fairness, which in turn impacted destination brand image.

We hope this special issue sheds light on some of the ethical and legal issues in pricing and RM particularly as they relate to the hospitality context. While a narrowly defined area of research in RM, manifestations of ethical and legal concerns in the RM practice are multi-faceted and are in dire need to be closely examined and addressed. It offers a futile avenue for research, particularly on how to better understand such phenomena in RM practice through a theoretical lens. The findings from research in such issues can help (hospitality) business implement more ethically defensible RM practices, encourage industry-wide self-regulation, and provide more empirical evidence for sound legislative oversight in protection of various stakeholders including consumers, business firms, employees, and the general public. It is also evident that we must not underestimate how important this area of research will be in future RM. There is a strong need for more research on developing and implementing fairer, ethical, and morally acceptable pricing and RM policies and practices. It is our hope that the articles included in this special issue provide some first building blocks for future research in this area. We look forward to seeing more scholarly attention on this critical and often underestimated aspect of pricing and RM.

To conclude, we would like to thank all the contributors to this special issues and all reviewers who generously offered their support by providing constructive feedback to each paper. We also feel privileged to have the opportunity to edit this special issue for JRPM and we would like to express our gratitude to Prof. Ian Yeoman for his support and guidance throughout the editorial process.

Publisher's Note Springer Nature remains neutral with regard to jurisdictional claims in published maps and institutional affiliations. 